\title{
BASIC GUIDELINES FOR PREPARING A CASE REPORT
}

\begin{abstract}
Introduction: The case report approach is a method of publication frequently used by clinicians to share data. The case report is a valuable research and education resource.

Purpose: The purpose of this article is to define a case report and to present basic guidelines for preparing a case report.

Method: The case report should include an introduction, literature review, case description, outcome section, discussion and summary. These components are presented and discussed briefly.
\end{abstract}

KEY WORDS: GUIDELINES, CASE REPORT, RESEARCH, EDUCATION, PUBLICATION

\section{BACKGROUND}

The case report approach is a method of publication frequently used by clinicians to share pertinent data about real-life situations with colleagues (Barr, 1995). Properly prepared, the case report is a valuable research and educational resource (DeBakey \& DeBakey, 1983). Case reports are generally more interesting than other forms of scientific communication because the human element adds an appeal that may be lacking in other research.

Even before Hippocrates, case reports have made a valuable contribution to the advancement of medical science (McCarthy \& Reilly, 2000). The word report comes from the Latin " reportare", meaning, "to bring back". The medical record begins when the patient first consults a practitioner, and it is enlarged with each subsequent visit (De Bakey \& De Bakey, 1983).

Case reports do not have to be unusual or unique to contribute to the body of knowledge. Case reports involving patients, should illustrate elements of patient management that have not yet been well described in the professional literature. Because of the overall lack of case reports in physiotherapy, a case report of almost any type of patient would meet these criteria (McEwen, 1996).

The purpose of the following article is to share with readers the definition of a case report and basic guidelines for preparing a case report.

\section{DEFINITIONS AND TERMS}

The terms "case report" and "case study" are sometimes used interchangeably and their definitions tend to overlap. The term "case report" refers to descriptions of practice that do not involve research methodology. A "case study" which may be similar in appearance to a "case report" refers to a type of research methodology and has procedures and standards of its own (McEwen, 1996)

It should be noticed that case studies or case reports are descriptive and lack experimental control (Barr, 1995). Case studies should not be confused with the single case experimental design, single subject research or $n=1$ study. Single subject research design studies or $n=1$ studies have their origins in clinical psychology and study the effects of intervention or behaviours on single individuals or small groups of individuals. They are non-randomised clinical trials (McEwen, 1996).

\section{GENERAL PRINCIPLES OF WRITING A CASE REPORT}

A well-written case report has a carefully designed structure (See table 1 for ideas on cases suitable for a case report). The author of a good case report has recorded observations punctiliously, analysed data scrupulously, and selected the most pertinent information for presentation using supplementary graphic or tabular material for easy interpretation. It requires it thus to be factual, concise, logically organized and clearly presented. Conciseness is essential in a case report, but conciseness does not mean cryptic or inept shorthand, such as obscure abbreviations or regional slang (DeBakey \& DeBakey, 1983).

\section{ESSENTIAL COM PONENTS OF THE CASE REPORT}

The case report should include an introduction, literature review, case description (case history, physical examination and intervention), outcome section, discussion and summary. These components will be discussed shortly.

An accurate, descriptive title, clearly indicating the subject should be formulated.

\section{INTRODUCTION}

The introduction gives the background to the case (announces the subject) and motivates and justifies the importance of the specific case. The problem statement and the purpose of the case needs to be realistic, clearly identified and demarcated and should correspond with the title.
CORRESPONDENCE TO:
M Papadopoulos
Department of Physiotherapy
University of Pretoria
P O Box 667
Pretoria 0001
Tel: (012) 354-2023 
Table 1: Cases suitable for case reports

- Cases that contribute to a change in the course of medical science (M cCarthy and
Reilly, 2000).
- Cases on the decision-making processes related to the examination, evaluation
and diagnoses (M CEwen, 1996). An unusual combination of conditions, cascading
events or presenting complaints that confused the decision-making process or
created treatment dilemmas can be reported on.
- Cases that demonstrate an adverse or good response to therapy or an intervention.
- Reports that describe the personal influence a particular event had on the patient,
the physiotherapist or both. A case that causes a physiotherapist to re-evaluate
how he or she cared for patients or a case that suggests opportunities for patient
education (M cCarthy $\&$ Reilly, 2000).

\section{LITERATURE REVIEW}

A review of the literature may help the clinician on deciding on the significance of the case. If numerous cases have already been cited in the literature, the clinician may need to decide if any new elements have been identified that justify or substantiate the need to publish the case report in question (Barr, 1995). A brief reference to the most significant earlier publications is generally adequate to link previous knowledge to the description and the discussion to follow. The literature review should start thus with a description of the index terms or MeSH heading (Medical Subject Heading) used for the searches, so that others can reproduce the search (McCarthy \& Reilly, 2000). The contents of the literature review should be descriptive, comparative and evaluative and shortcomings of the literature should be clearly indicated. Although a concise overview of the pertinent literature is necessary in a case report, a full-scale literature review is not necessary. Citation of a recent comprehensive review, when available, may be sufficient to show the relation of the present case(s) to previous reports. However, finding such a review does not relieve the author of the responsibility of making a comprehensive search of publications on the subject, an essential part of preliminary preparation (DeBakey \& DeBakey, 1983). All citations should be included in the reference list at the end of the manuscript (according to the required guidelines for the specific journal where publication is planned).

The case description consists of the case history, physical examination and intervention.

\section{CASE HISTORY}

The case history should begin with an introduction to the patient and should provide a history of the current situation. Care should be taken not to report on the identity of the patient for example by publishing the patient's name, his initials or the name of the reporting institution. Conventionally, identification includes the patient's age, sex and when pertinent, race or ethnic origin and occupation. Even when this information does not seem particularly significant to the case being reported, it might be of interest to epidemiologists or other researchers (DeBakey \& DeBakey, 1983). A pertinent diagnoses and medical history, demographic characteristics, including pertinent psychological, social and environmental factors should follow. Comorbidities that may affect the goals and treatment plan should also be mentioned. A statement of the patient's knowledge of the problem and the goals and/or expectance of the patient regarding treatment should be provided.

\section{PHYSICAL EXAMINATION}

Details about the physical examination and any test results that provide insight into the case should be included. The physical examination should be appropriate and realistic to the patient's problem and authors should refrain from providing unnecessary test results. In physiotherapy, it is of utmost importance that the physical examination is replicable and operational definitions of procedures should therefore be used.

There is always an element of uncertainty in dealing with reliability, therefore it is essential that in a case report some evidence should be provided that mea- surements adequately reflect the status of the patient and not measurement error. Measurements taken during the physical examination should be reliable by referencing a reliability study, by conducting a mini-reliability study or by making a presumptive argument. Referencing a reliability study may be the most common and sound way of providing evidence for acceptable reliability of measurements in a case report. Published reliability studies can be found through a literature search. Therapists who use measurements that have a pre-established level of reliability can be reasonably certain that their measurements are reliable assuming that they followed the operational definitions of standardized procedures for the measurement. The purpose of a mini-reliability study is to determine the consistency of measurements taken more than once by the same clinician (intratester reliability) or taken by two or more clinicians (intertester reliability). When making a presumptive argument the author develops a theoretical argument that supports the notion that the measurement adequately represents the variable of interest and has an acceptable level of reliability. This method should be the method of last resort and should be used only when published reliability studies do no exist and it is not possible to do a mini-reliability study (McEwen, 1996).

\section{INTERVENTION}

After gathering and analysing the initial subject information and the examination data, the next step is to describe what was done to reach the identified goals. The rationale for treatment should be closely linked to the hypothesized cause of the patient's problem. Because case reports lack the controls of experimental studies, hypotheses cannot be tested in the same way they are tested in research. Hypotheses are tested informally. In addition to explaining why the intervention was selected and why it changed over time, authors must describe how the intervention was applied so clearly and completely that another physiotherapist could replicate the intervention with a similar patient (McEwen, 1996). Patient adherence to treatment protocol is also an important issue to address in 
all case reports that describe treatment implementation.

Tables, flow charts, photographs, radiographs or figures can be included to elucidate the case history, physical examination or intervention. When photographs are used, permission should be obtained from the patient and identifying features should be blocked out so that the patient's privacy is protected. The challenge is to determine which format will complement the text and operationally define the examination or intervention the best.

\section{OUTCOMES}

For the purpose of a case report, outcome is defined as the status of the subject(s) following intervention. Outcomes can be measured using one or more of the measurement tools designed to assess the patient's ability to function. Changes that occurred should be recorded as changes in functional abilities. It is not adequate to describe changes in terms of range of motion or pain for instance. Case reports are strengthened if the patient's reports of progress are obtained during the course of treatment as well as at the end of treatment, and if long-term follow-up information is obtained, even from a telephone call (McEwen, 1996). It is important to remember that if incomplete or inaccurate data is obtained no valid conclusions can be drawn. Precise figures should be given, with the normal range in parentheses, as different readers may variously interpret the expression "normal range".

Outcomes can be presented in text, tables, photographs or a variety of figures.

\section{DISCUSSION}

The discussion section is the most important section of a case report. This is where the author states the significance of the information. The discussion should provide the link back to the purpose of the case report and to the literature, reflect on the case management and outcomes, suggest possible alternative explanations for the outcomes and pose questions for further research (McEwen, 1996). The discussion section should discuss the relevant literature in the context of the current case, describing why the case being reported is a new and noteworthy or unique observation (McCarthy \& Reilly, 2000). Anticipate and discuss adequately any alternative explanations or possibilities others may advance (DeBakey \& DeBakey, 1983). Because many variables in the case report are not controlled when collecting and analysing data, the clinician must attempt to look at any possible effects of this fact.

\section{Table 2: Case report worksheet}

\begin{tabular}{|c|c|c|}
\hline Heading & Special features & Personal notes \\
\hline Title & Accurate, descriptive, clearly indicating the subject of the investigation. & \\
\hline Introduction & $\begin{array}{l}\text { Background to the topic, motivates and justifies the importance of the case. } \\
\text { Problem statement, aim and purpose should be appropriate, realistic, } \\
\text { clearly demarcated and correspond with the title. }\end{array}$ & \\
\hline Literature review & $\begin{array}{l}\text { Literature should be appropriate, applicable and critically evaluated. } \\
\text { Contents should be descriptive, comparative and evaluative and } \\
\text { shortcomings should be indicated. }\end{array}$ & \\
\hline Case history & $\begin{array}{l}\text { History of the presenting problem, pertinent diagnosis and medical history. } \\
\text { Demographic characteristics (including psychological, social and } \\
\text { environmental factors), comorbidities and patient's knowledge of the } \\
\text { problem should be included. } \\
\text { O nly data/ details relevant to the patient problem. }\end{array}$ & \\
\hline Physical examination & $\begin{array}{l}\text { Should be replicable, appropriate and realistic to patient's problem. } \\
\text { Measurements (operational definitions should be supplied) should be } \\
\text { reliable by: referencing a reliability study, performing a mini-reliability } \\
\text { study or by using a presumptive argument (M cEwen, 1996). }\end{array}$ & \\
\hline Intervention & $\begin{array}{l}\text { Clear, replicable descriptions or operational definitions of procedures used } \\
\text { should be supplied. } \\
\text { Patient adherence and participation should be addressed (M cEwen, 1996). }\end{array}$ & \\
\hline O utcomes & $\begin{array}{l}\text { O utcome measures should be appropriate and short-and long-term } \\
\text { follow-up should be described. Changes in patient functional abilities } \\
\text { should be described (McEwen, 1996). }\end{array}$ & \\
\hline Discussion & $\begin{array}{l}\text { Should link the case back to its purpose/ aim and relate the case to the } \\
\text { literature. Author should give his own viewpoint and anticipate any } \\
\text { alternative explanations or possibilities others may advance (Barr, 1995). }\end{array}$ & \\
\hline Summary & $\begin{array}{l}\text { Limitations identified in the case report should be clearly stated. } \\
\text { Recommendations for clinical practise or for future research should } \\
\text { be very specific. }\end{array}$ & \\
\hline
\end{tabular}




\section{SUMMARY}

The case report should include a brief summary, conclusion or recommendation section - the take home message (McCarthy \& Reilly, 2000). Conclusions, which state the clinician's personal judgement about facts uncovered, can be stated. Generalisations cannot go beyond the data collected and must be confined to the case report. It is necessary to make sure that any limitations identified in the case report are clearly stated (Barr, 1995). Recommendations for clinical practise as well as recommendations for future research should be included. This section should be brief, only one or two paragraphs.

\section{PUBLISHING A CASE REPORT}

Journals print their required instructions for authors regularly and these instructions should be consulted early in the writing process so that the manuscript can be prepared in the appropriate style. When the manuscript is received by the journal, it will go through a brief editorial review to determine potential suitability followed by a peer-review process. These comments from reviewers help authors revise and edit manuscripts, which can then be resubmitted for publication.

The case report approach is an appropriate and effective method for a clinician to share information with colleagues. The attached case report worksheet (see table 2) can be used to organise scientific observations into interesting and publishable case reports. A useful case report is factual, concise, logically organized, clearly presented and readable: make sure the case warrants publication, include only pertinent information and be concise (DeBakey \& De Bakey, 1983).

\section{REFERENCES}

Barr JE 1995 Research \& writing basics: elements of the case study. Ostomy wound management 41(1):18, 20-1 Jan-Feb.

DeBakey L \& DeBakey S 1983 The case report. I. Guidelines for preparation. International Journal of Cardiology 4: 357-364.

McCarthy LH \& Reilly KEH 2000 How to write a case report. Family Medicine 32(3): 190-195.

McEwen I 1996 Writing case reports: A how-to manual for clinicians. A publication of the American Physical Therapy Association, Alexandria, Virginia.

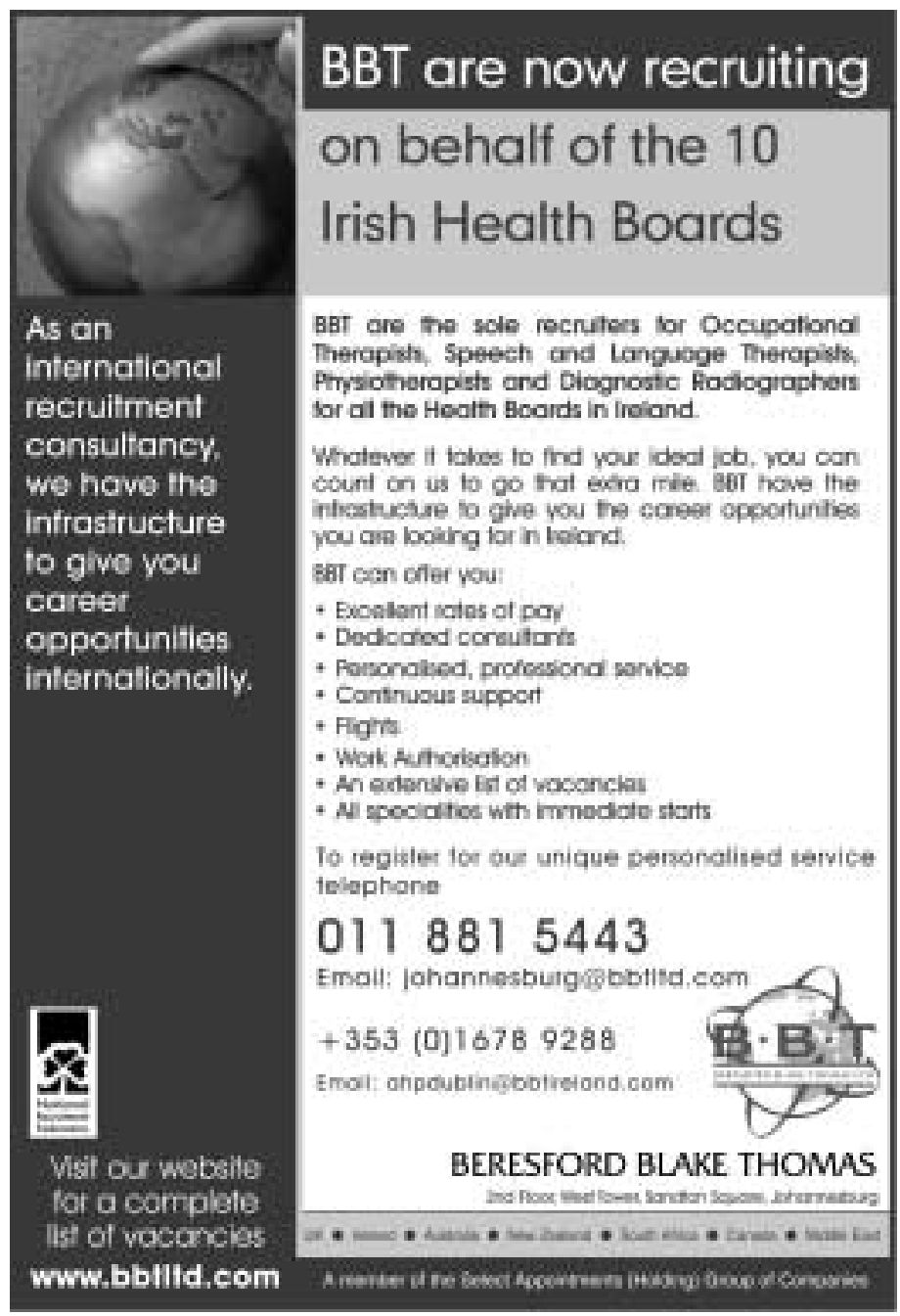

\section{Develop your Career in the UK}

Immediate vacancies throughout the UK
for Physiotherapists...

*Visa fee re-imbursement

- Immigration advice *

Meet and greet service $\cdot$

Accommodation assistance *

Bank account •

Excellent pay *

Free financial advice *

Personal development fund •

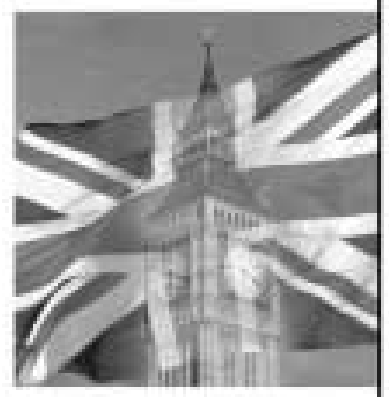

Cape Town:

(021) $6805146 \quad$ (012) 3624523

\section{THERAPY \\ wo $0 \times 1+4 \pi$}

seard our pobse

whw.therapy-workline.co.uk

t: southatricaestherapy worklins,couk 